\title{
Random duodenal biopsy to exclude coeliac disease as a cause of anaemia is not cost-efective and should be replaced with universally performed pre-endoscopy serology in patients on a suspected cancer pathway
}

\author{
P. J. J. Herrod ${ }^{1,2}$ (D) J. N. Lund ${ }^{1,2}$ (D)
}

Received: 23 October 2017 / Accepted: 20 December 2017 / Published online: 23 February 2018

(c) The Author(s) 2018. This article is an open access publication

\begin{abstract}
Background Random duodenal biopsy to exclude coeliac disease during upper gastrointestinal endoscopy for the investigation of iron deficiency anaemia remains a common procedure, but is expensive and time-consuming. Serological investigation for coeliac disease is also recommended, having excellent accuracy with the added benefit of lower cost. This study sought to examine the utility of duodenal biopsy and coeliac serology in the diagnosis of coeliac disease.

Methods A prospectively maintained database was interrogated to identify all patients having upper gastrointestinal endoscopy for the investigation of anaemia between January 01, 2016, and December 31, 2016.

Results Of the 1131 patients having an endoscopy, coeliac serology was measured in only 412 (36\%) and was positive in 9 cases (2\%), leading to 6 histological diagnoses of coeliac disease and 3 false positives. Two-hundred and seventy-four patients with negative serology had biopsies taken which were all negative. Only $2 / 451(0.4 \%)$ patients who had biopsies performed in the absence of a serology test were histologically positive for coeliac disease. The cost per diagnosis of a case of coeliac disease in those with either negative or absent coeliac serology was $£ 18,839$ (US\$25,244, €21,196).

Conclusions Random duodenal biopsy is not a cost-effective method of diagnosing coeliac disease and should be replaced with pre-endoscopy coeliac serology.
\end{abstract}

Keywords Celiac disease $\cdot$ Serologic tests $\cdot$ Endoscopy $\cdot$ Anaemia $\cdot$ Iron deficiency $\cdot$ Biopsy $\cdot$ Colorectal cancer

\section{Introduction}

Investigation of anaemia represents a large workload for endoscopy services [1] with anaemia cited as the primary indication in up to $10 \%$ of gastroscopies and $6 \%$ of colonoscopies [2]. In 2015, 756,600 upper gastrointestinal (GI) endoscopies were carried out in England alone [3]. In the UK, a large burden of this endoscopy workload falls upon colorectal surgeons as the National Institute for Health and Care Excellence (NICE) recommends referral of patients

\section{P. J. J. Herrod}

pherrod@nhs.net

1 Department of Surgery, Royal Derby Hospital, Derby DE22 3NE, UK

2 Division of Medical Sciences and Graduate Entry Medicine, Royal Derby Hospital, University of Nottingham, Derby, UK with iron deficiency anaemia (IDA) to a colorectal clinic under the 2-week wait pathway [4].

Luminal investigation remains the gold standard for investigation of possible malignancy with sensitivities and specificities approaching 100\% [5-7]. However, upper GI cancer is one of the rarer causes of IDA with as few as $2 \%$ of luminal investigations finding malignancy as the cause [8].

Other upper GI causes of anaemia include use of nonsteroidal anti-inflammatory drugs, peptic ulceration and peptic erosions, the majority of which can be detected through visual assessment of the mucosa alone [9]. Coeliac disease is also a common cause of IDA, often diagnosed by demonstration of microscopic features of the disease in duodenal biopsy [10]. Macroscopic features are mostly absent [11, 12], and so biopsy of normal looking mucosa is recommended by the British Society of Gastroenterology and other bodies in order to exclude coeliac disease as a cause of IDA $[10,13,14]$. 
Highly sensitive and specific immunological assays for the diagnosis of coeliac disease have been developed during the past 2 decades, and the use of the coeliac serology is recommended in the investigation of IDA [15]. The tests are now so reliable that some authors suggest that biopsy is not always necessary for the diagnosis of coeliac disease $[16,17]$.

Despite these developments, it remains usual for endoscopists to take random duodenal biopsies in the investigation of IDA to exclude coeliac disease as a cause based on traditional practice and content of guidelines [10, 13]. However, duodenal biopsy carries potential morbidity and mortality $[18,19]$ and increases financial costs due to biopsy equipment, specimen processing and reporting time. This study aimed to evaluate the utility and cost of random duodenal biopsies compared to serology in the diagnosis of coeliac disease in patients being investigated for IDA in one teaching hospital in the UK.

\section{Materials and methods}

This study was carried out as a service evaluation in a large teaching hospital in the UK, which performs over 9000 upper GI endoscopies each year.

All patients having upper GI endoscopy between January 01, 2016, and December 31, 2016, for investigation of anaemia were identified via a prospective electronic database.

Results of haematological, biochemical and immunological investigations performed prior to endoscopy were obtained from the hospital pathology computer database. Similarly, results of duodenal biopsy were retrieved from the pathology records. Internal National Health Service costs for the processing of serology, histology and biopsy consumables were obtained from the hospital finance department.

Data were analysed using Microsoft Excel (version 2016, Microsoft, USA).

\section{Results}

In total, 1150 upper GI endoscopies were carried out for the investigation of anaemia in the 2016 calendar year on 1131 patients. Only $886 / 1131$ patients investigated for anaemia had microcytosis (MCV < 88.0) and only 159 patients had their serum ferritin measured in the investigation of their anaemia. Fifteen patients had an upper GI endoscopy for investigation of anaemia with no evidence of their serum haemoglobin concentration being below $135 \mathrm{~g} / \mathrm{l}$ at any time.

Four hundred and twelve patients (36\%) had coeliac serology performed prior to their endoscopy. Seven hundred and thirty-four patients (65\%) had duodenal biopsy. A Strengthening the Reporting of Observational Studies in Epidemiology (STROBE) flow diagram demonstrating the clinical pathway followed by all patients having an upper GI endoscopy is displayed in Fig. 1.

Coeliac serology was positive in $9 / 412$ patients $(2.2 \%)$ in whom it was measured before the procedure. All 9 of these also had duodenal biopsy performed at endoscopy,

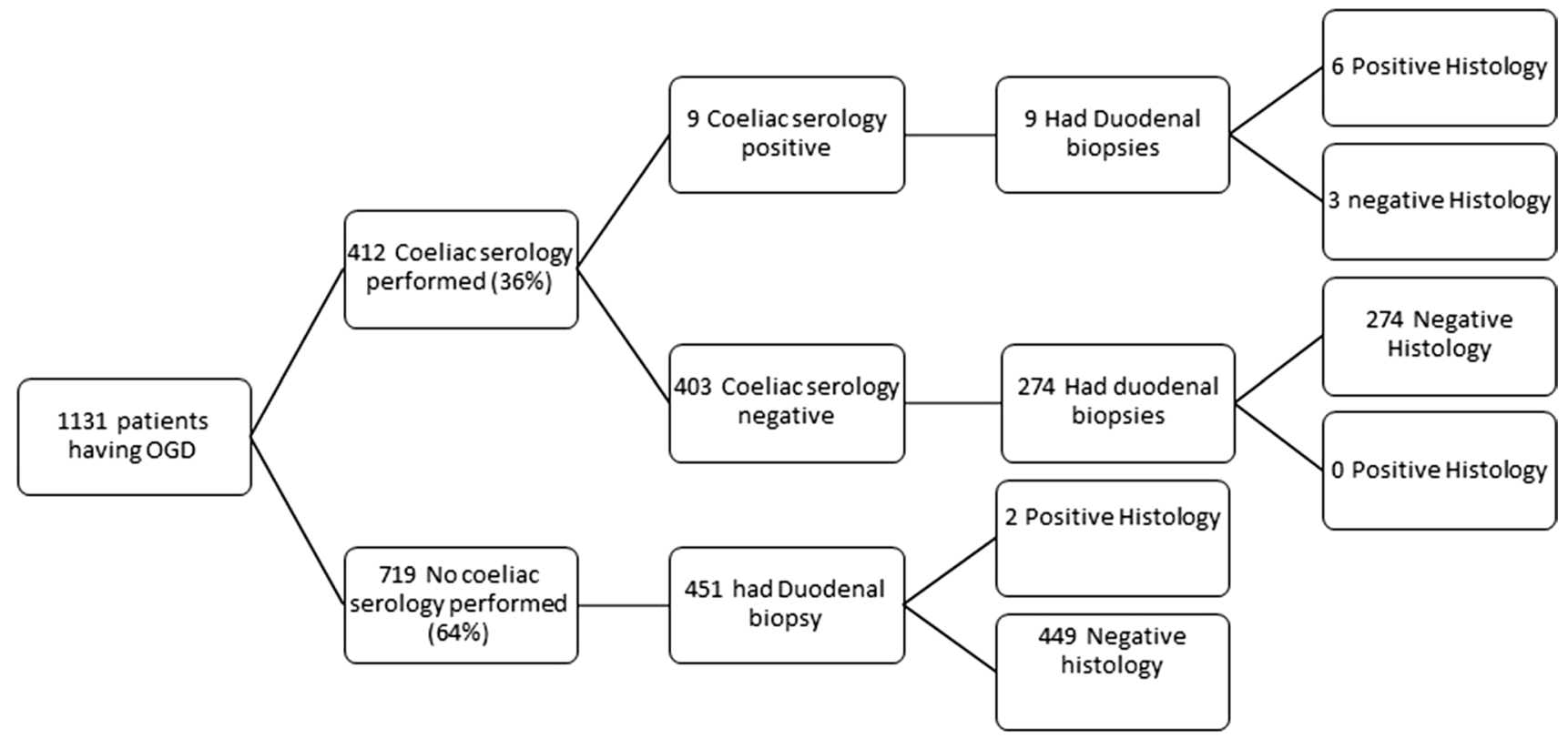

Fig. 1 Strengthening the reporting of observational studies in epidemiology flow diagram demonstrating clinical course of patients having an upper gastrointestinal endoscopy 
which was positive for histological markers of coeliac disease in 6 cases and was negative in 3 cases. Of the 403 patients with negative serology, 274 (68\%) had duodenal biopsy, none of which demonstrated coeliac disease (249 biopsies reported as normal and 18 as non-specific inflammatory change). Coeliac serology therefore yielded 3 false positive results and no false negatives making the test $100 \%$ sensitive and $99 \%$ specific.

Of the 719 patients without pre-procedure coeliac serology, 451 had duodenal biopsy (63\%), 2 were positive for coeliac disease $(0.4 \%)$, non-specific inflammatory changes were reported in 37, and the remaining 394 patients had biopsies reported as normal.

The internal National Health Service cost price for the processing of an IgA TTG (tissue trans-glutaminase) titre (the serological test used in our institution) is £6.54 (US\$8.73, €7.36). The cost for consumables used in duodenal biopsy is $£ 4.75$ for each patient and the cost of processing and reporting each duodenal biopsy $£ 47.22$ (\$63.06, $€ 53.13)$.

The total cost of processing the duodenal biopsies in our institution in one calendar year for the investigation of anaemia was $£ 38,146(\$ 50,943, € 42,934)$. $£ 37,678$ was spent processing biopsies from patients who were either TTG negative or had not had their TTG measured, leading to the detection of coeliac disease in 2 patients who had not had TTG performed: a cost of $£ 18,839(\$ 25,244, € 21,196)$ per case. The cost of measuring TTG in the 719 patients who did not have it performed would have been $£ 4702$ (\$6278, $€ 5290)$.

\section{Discussion}

This study suggests that random duodenal biopsy is not costeffective for the diagnosis of coeliac disease as a cause of IDA and should be abandoned in favour of immunological tests. Whilst serology will not identify all cases of coeliac disease, these tests are 96-98\% sensitive and 95-99\% specific [20]. In our 1 year of investigation of IDA, 2 patients with coeliac disease who did not have pre-procedure serology were identified by biopsy. The extra cost of identifying each of these cases using a non-selective duodenal biopsy policy was $£ 18,839$ per case, far in excess of costs of diagnosing colorectal cancer in practice (between $£ 7586$ and $£ 9663$ per patient) [21] and is difficult to justify in any financial climate [22, 23]. Indeed, it is almost certain, given the sensitivity of the immunological test, that these cases would have been identified by serology, had it been performed before endoscopy.

With cheap and reliable serological tests, coeliac disease can be excluded without duodenal biopsy [16, 17]. Our experience suggests that performing biopsy on those with negative TTG is unnecessary and more expensive, and although none were seen in our patients, others report a small risk of complications associated with biopsy $[18,19]$.

The increased costs of biopsy over serology may be underestimated in this study as we have not costed clinical administration time, consumables and postage involved in communicating the result of the biopsy to patient and general practitioner, nor the delay in informing the patient of the outcome of the biopsy. The result of a pre-endoscopy TTG test performed on referral for endoscopy would be ready for patient and endoscopist at the time of the endoscopy and would help to rationalise biopsy practice. Insufficient workup for IDA remains an issue in this group of patients [24]. Although there were no false negative serology results in our year-long series, continued anaemia after iron therapy or an ongoing suspicion of a potential missed diagnosis of coeliac disease should prompt random duodenal biopsy even if serology is negative, as advised by NICE [13].

\section{Conclusions}

Random duodenal biopsy to exclude coeliac disease as a cause of anaemia is not cost-effective and should be replaced with universally performed pre-endoscopy TTG.

Acknowledgements Philip Herrod is supported by a research training fellowship jointly awarded by the Royal College of Surgeons of England and the Dunhill Medical Trust. The authors would like to thank Jane McEvoy, Endoscopy unit manager at the Royal Derby Hospital, for her help with case identification.

Funding Philip Herrod is supported by a research training fellowship jointly awarded by the Royal College of Surgeons of England and the Dunhill Medical Trust.

\section{Compliance with ethical standards}

Conflict of interest The authors declare that they have no conflict of interest.

Ethical approval This study was registered as a service evaluation with the hospital endoscopy department.

Informed consent This was a retrospective service evaluation, thus consent was not required.

Open Access This article is distributed under the terms of the Creative Commons Attribution 4.0 International License (http://creativeco mmons.org/licenses/by/4.0/), which permits unrestricted use, distribution, and reproduction in any medium, provided you give appropriate credit to the original author(s) and the source, provide a link to the Creative Commons license, and indicate if changes were made. 


\section{References}

1. The Association of Coloproctology of Great Britain and Ireland, British Society of Gastroenterology, Association of Upper Gastrointestinal Surgeons of Great Britain and Ireland (2013) Guidance on the indications for diagnostic upper GI endoscopy, flexible sigmoidoscopy and colonoscopy. http://www.bsg.org.uk/images/stori es/docs/clinical/guidance/indications_diagnostic_endoscopy_13. pdf. Accessed 7 Jul 2017

2. National Institute of Health (2008) Burden of digestive diseases in the United States report. https://www.niddk.nih.gov/about-niddk /strategic-plans-reports/Pages/burden-digestive-diseases-in-unite d-states-report.aspx\#CHAPTER24. Accessed 7 Jul 2017

3. JAG (2016) Joint advisory group on GI endoscopy 2016 GRS census-analysis of responses NHS acute units in England background. http://www.thejag.org.uk/downloads/National. Policies and reports/JAG GRS census 2016 - analysis of service information_v1.zip. Accessed 7 Jul 2017

4. NICE (2017) Suspected cancer recognition and referral: primary care investigation findings. http://pathways.nice.org.uk/pathw ays/suspected-cancer-recognition-and-referral/suspected-cance r-recognition-and-referral-primary-care-investigation-findings. pdf. Accessed 19 Oct 2017

5. Voutilainen ME, Juhola MT (2005) Evaluation of the diagnostic accuracy of gastroscopy to detect gastric tumours: clinicopathological features and prognosis of patients with gastric cancer missed on endoscopy. Eur J Gastroenterol Hepatol 17:1345-1349

6. Bloomfeld RS, Bridgers DI, Pineau BC (2005) Sensitivity of upper endoscopy in diagnosing esophageal cancer. Dysphagia 20:278-282

7. Garborg K, Holme $\emptyset$, Løberg M, Kalager M, Adami HO, Bretthauer M (2013) Current status of screening for colorectal cancer. Ann Oncol 24:1963-1972

8. Shawihdi M, Thompson E, Kapoor N et al (2014) Variation in gastroscopy rate in English general practice and outcome for oesophagogastric cancer: retrospective analysis of hospital episode statistics. Gut 63:250-261

9. Majid S, Salih M, Wasaya R, Jafri W (2008) Predictors of gastrointestinal lesions on endoscopy in iron deficiency anemia without gastrointestinal symptoms. BMC Gastroenterol 8:52

10. Ludvigsson JF, Bai JC, Biagi F et al (2014) Diagnosis and management of adult coeliac disease: guidelines from the British Society of Gastroenterology. Gut 63:1210-1228

11. Freeman HJ (2008) Pearls and pitfalls in the diagnosis of adult celiac disease. Can J Gastroenterol 22:273-280
12. Freeman HJ (1998) Survey of gastroenterologists on the diagnosis and treatment of adult patients with celiac disease in British Columbia. Can J Gastroenterol 12:149-152

13. NICE (2015) Coeliac disease: recognition, assessment and management. https://www.nice.org.uk/guidance/ng20/resources/coeli ac-disease-recognition-assessment-and-management-pdf-18373 25178565. Accessed 19 Oct 2017

14. Rubio-Tapia A, Hill ID, Kelly P, Calderwood AH, Murray JA (2013) ACG clinical guidelines: diagnosis and management of celiac disease. Am J Gastroenterol 108:656-676

15. Goddard AF, McIntyre AS, Scott BB (2011) Guidelines for the management of iron deficiency anaemia. Gut 46:iv1-iv5

16. Hill PG, Holmes GKT (2008) Coeliac disease: a biopsy is not always necessary for diagnosis. Aliment Pharmacol Ther 27:572-577

17. Holmes GKT, Forsyth JM, Knowles S, Seddon H, Hill PG, Austin AS (2017) Coeliac disease: further evidence that biopsy is not always necessary for diagnosis. Eur J Gastroenterol Hepatol 29:640-645

18. Diniz-Santos DR, de Andrade Cairo RC, Braga H, Araújo-Neto C, Paes IB, Silva LR (2006) Duodenal hematoma following endoscopic duodenal biopsy: a case report and review of the existing literature. Can J Gastroenterol 20:39-42

19. Scott B, Holmes G (1993) Perforation from endoscopic small bowel biopsy. Gut 34:134-135

20. Rostom A, Dubé C, Cranney A et al (2005) The diagnostic accuracy of serologic tests for celiac disease: a systematic review. Gastroenterology 128:S38-S546

21. Peacock O, Clayton S, Atkinson F, Tierney GM, Lund JN (2013) Be clear on cancer: the impact of the UK national bowel cancer awareness campaign. Colorectal Dis 15:963-967

22. Burger JPW, Meijer JWR, Wahab PJ (2013) Routine duodenal biopsy to screen for coeliac disease is not effective. Neth J Med 71:308-312

23. Yang JJ, Thanataveerat A, Green PHR, Lebwohl B (2015) Cost effectiveness of routine duodenal biopsy analysis for celiac disease during endoscopy for gastroesophageal reflux. Clin Gastroenterol Hepat 13:1437-1443

24. Shaw AG, Simpson J, Tierney G, Goddard AF, Reynolds JR, Lund JN (2008) Referral of patients with iron deficiency anaemia under the lower gastrointestinal two-week wait rule. Colorectal Dis 10:294-297 